\begin{tabular}{|l|l|l||}
\hline \multicolumn{2}{|c|}{ PublisherInfo } \\
\hline \hline PublisherName & $:$ & BioMed Central \\
\hline \hline PublisherLocation & $:$ & London \\
\hline \hline PublisherImprintName & $:$ & BioMed Central \\
\hline \hline
\end{tabular}

\title{
Nitric oxide in ALI
}

\begin{tabular}{|l|l|l||}
\hline \multicolumn{2}{|c|}{ ArticleInfo } \\
\hline \hline ArticleID & $:$ & 4161 \\
\hline \hline ArticleDOI & $:$ & $10.1186 /$ ccf-1999-2181 \\
\hline \hline ArticleCitationID & $:$ & 2181 \\
\hline \hline ArticleSequenceNumber & $:$ & 20 \\
\hline \hline ArticleCategory & $:$ & Paper Report \\
\hline \hline ArticleFirstPage & $:$ & 1 \\
\hline \hline ArticleLastPage & $:$ & 4 \\
\hline \hline & & RegistrationDate : 1999-10-26 \\
\hline ArticleHistory & $:$ & OnlineDate $1999-10-26$ \\
\hline \hline ArticleCopyright & $:$ & Current Science Ltd1999 \\
\hline \hline ArticleGrants & $:$ & \\
\hline \hline ArticleContext & $:$ & 1305422 \\
\hline \hline
\end{tabular}




\section{Keywords}

Acute respiratory failure, mechanical ventilation, nitric oxide, pulmonary artery pressure

\section{Comments}

This trial confirms previous results that $\mathrm{NO}$ shows important physiological benefits in a group of patients with ALI, but does not improve outcome. Improvement in arterial oxygenation may not be enough to compensate for the dying cell that is finding it difficult to utilise oxygen, and so the relentless course to multi-organ failure fails to be halted. Alternatively, as other authors have suggested, the group of patients studied (those with acute respiratory distress syndrome) was too heterogeneous and we need to be defining subgroups that may benefit from NO therapy. Although we should take note of the higher incidence of renal failure in the NO treated group, it may well be that this is a chance finding, since there is no physiological mechanism or previous animal data to advocate renal toxicity.

\section{Introduction}

The physiological effects of inhaled nitric oxide (NO) are well known in the acute respiratory distress syndrome; improvements in oxygenation and reductions in pulmonary hypertension have been repeatedly described. However these observations have failed to translate into improvements in outcome in published trials.

\section{Aims}

Primary endpoint: to determine whether NO improves the rate of reversal of acute lung injury (ALI). Secondary endpoint: long-term safety of NO therapy, incidence of progression to severe respiratory failure (SRF), 30 and 90 day mortality.

\section{Methods}


A prospective, multicentre, randomised, controlled study investigating patients with ALI who had been ventilated for $<96 \mathrm{~h}$. A dose response test with $\mathrm{NO}$ was performed at $0,2,10$, and 40 ppm to identify NO responders - those patients whose $\mathrm{PaO}_{2}$ increased by $25 \%$ for the first 140 patients and $20 \%$ for the remainder, following a protocol amendment. Responders were randomised to receive either conventional therapy alone, or NO and conventional therapy. Stratification was also changed after the first 140 patients from high/low APACHE II score to high/low $\mathrm{PaO}_{2} / \mathrm{FIO}_{2}$ ratios. Non-responders were followed up and the three groups were analysed. End points were defined, although definition for reversal of ALI was again changed after 140 patients. Safety measures included monitoring of methaemoglobin and organ failure.

\section{Results}

In total, 268 patients were studied - $180(67 \%)$ responders and 88 non-responders. Patient characteristics were well matched in the three groups. There were no differences between the groups in frequency of reversal of ALI and mortality. Fewer patients developed SRF in the NO group (two patients) compared to conventional therapy (nine patients) in responders. Analysis of safety data revealed a higher incidence of renal replacement therapy and/or increases in creatinine, following randomization, in the NO treated group.

\section{Discussion}

Improvements in oxygenation and a reduction in pulmonary artery pressure were seen in a group of patients with ALI, as shown in previous studies. However outcome measures were not improved by NO in a group of patients who showed a beneficial physiological response to NO. The authors highlight the weaknesses of this study; the target of 600 recruited patients was never achieved (study stopped early by sponsor because of slow recruitment), and study amendments occurred after the recruitment of 140 patients (to try and improve recruitment). The higher incidence of renal failure in the NO group has not been seen in previous studies with NO, and may be a result of investigator bias since the timing of initiation of renal replacement therapy was not part of the protocol.

\section{Additional information}

This paper has an accompanying editorial. 


\section{References}

1. Lundin S, Mang H, Stenqvist O, Stenqvist O : Inhalation of nitric oxide in acute lung injury: results of a European multicentre study. Intensive Care Med . 1999, 25: 911-919.

This PDF file was created after publication. 